\title{
Representação do conceito de mulher na Classificação Decimal Dewey (CDD) a na Classificação Decimal Universal (CDU): duas perspetivas sobre o mesmo conceito?
}

The representation of woman's concept in the Decimal Dewey Classification (DDC) and in the Universal Decimal Classification (UDC): two perspectives for the same concept?

\author{
Maria da Graça Simões* \\ Blanca Rodríguez Bravo** \\ Olivia Pestana ${ }^{* * *}$
}

\section{RESUMO}

A dinâmica e a emergência de novos conhecimentos exige que se construam novos sistemas de organização de conhecimento e se revejam outros, para a sua localização e acesso. Nesse processo, as estruturas de organização do conhecimento assumem particular relevância como instrumentos eficazes de efetuar esses propósitos. Pela sua longevidade, destacam-se as classificações bibliográficas, entre as quais a Classificação Decimal de Dewey (CDD) e a Classificação Decimal Universal (CDU). Propõe-se como objetivo identificar como esses dois sistemas representam o conceito mulher e se tal pode ser considerado indicador de duas perspetivas sobre o mesmo conceito. Adotou-se uma abordagem qualitativa exploratória, baseada na revisão da literatura e análise comparativa da representação desse conceito nos dois

\begin{abstract}
The dynamics and emergence of new knowledge requires building new knowledge organization systems and reviewing others for the location and access of knowledege. In this process the structures of knowledge organization assume particular relevance, as effective instruments to accomplish these purposes. For its longevity, the bibliographical classifications stand out and among them particularly the Dewey Decimal Classification (CDD) and the Universal Decimal Classification (CDU). It is proposed to identify how these two systems represent the concept of woman and whether this can be considered as an indicator of two perspectives on the same concept. A qualitative exploratory approach was adopted, based on literature review and comparative analysis of the representation of this concept in the two systems considered.
\end{abstract}

\footnotetext{
* Doutora em Ciência da Informação, Universidad de Salamanca (España) - Metodologia y Líneas de Investigación en Biblioteconomía y Documentación. Professora auxiliar do Curso de Ciência da Informação da Faculdade de Letras da Universidade de Coimbra. Endereço: Largo Porta Férrea, 3000370, Coimbra. Portugal.Telefone: 239859900. E-mail: gsimoesuc@gmail.com

** Doutora em Historia. Professora titular, Área de Biblioteconomía y Documentación, Departamento de Patrimonio Artístico y Documental, Facultad de Filosofía y Letras, Universidad de León, 24071, León, Espanha. Telefone: +34987291469. E-mail: blanca.rodriguez@unileon.es.

*** Doutora em Informação e Comunicação em Plataformas Digitais. Professora auxiliar da Faculdade de Letras da Universidade do Porto. Endereço: Via Panorâmica, s/n, 4150-564, Porto, Portugal. Telefone: +351226077 100. E-mail: opestana@letras.up.pt.
} 
sistemas considerados. Não se observam duas perspetivas diferentes em relação ao conceito mulher, os dois sistemas continuam a traduzir a mentalidade positivista na qual foram concebidas. É evidente a reduzida representatividade do conceito mulher nos dois sistemas de classificação no que se refere à exaustividade e à especificidade. Os dois sistemas refletem a noção de mulher num plano depreciativo e inferior à masculina, traduzindo o estereótipo tradicional.

Palavras-chave: Mulher; Classificação Decimal Dewey (CDD); Classificação Decimal Universal (CDU).
Two different perspectives are not observed in relation to the woman's concept, because the two systems continue to translate the positivist mentality in which they were conceived. The low representativeness of the concept of woman in the two classification systems is evident with regard to exhaustivity and specificity. Both systems reflect the notion of woman in a depreciative and inferior plan to the masculine, translating the traditional stereotype.

Keywords: Woman; Dewey Decimal Classification; Universal Decimal Classification.

\section{INTRODUÇÃO}

A conquista de novos horizontes concorre para um contínuo desenvolvimento e crescimento do conhecimento humano. Novos campos emergem quando concebemos ideias inovadoras, melhoramos os nossos métodos científicos e inventamos novas tecnologias. Como resultado deste progresso dinâmico, reveem-se os livros antigos e escrevem-se novos, os quais manifestam e preservam esse conhecimento (ZINS; SANTOS, 2011). Para a localização e acesso a este conhecimento é necessário que ele seja organizado. Nessa linha, as estruturas de organização do conhecimento assumem particular relevância, como instrumentos eficazes para executar esses propósitos. Entre elas, pela sua longevidade e prova cabal, nessa tarefa, destacam-se as classificações bibliográficas. Esses sistemas de representação e organização da informação e do conhecimento foram ao longo do tempo adequando-se às novas dinâmicas sociais, culturais e mentais da sociedade. Para tal, recorreram a expedientes para representarem os novos conceitos, em alguns casos caraterizados pela sua evolução e complexidade semântica, produto da interdisciplinaridade, desenvolvida e consolidada ao longo do século XX (SIMÕES, 2011). Neste sentido, em meados da década de 1990, assistiram-se a alterações epistêmicas na área da organização do conhecimento, nomeadamente quando os investigadores começaram a reconhecer as influências sociais das classificações (FOX, 2016).

As teorias clássicas das classificações e do conceito baseadas na lógica da cultura grega, em particular na aristotélica, foram amplamente criticadas por feministas, investigadores de grupos marginalizados e bibliotecários especializados na sua aplicação, devido à sua rigidez e aos seus limites concetuais, em parte provocados por uma estrutura hierárquica e pelas suas implicações em termos de dominância e subordinação, que caracterizam as primeiras classificações bibliográficas de base enumerativa concebidas nos finais do século XIX e inícios do século XX, como são o caso da Classificação da Biblioteca do Congresso, Classificação Decimal Dewey e Classificação Decimal Universal (SIMÕES, 2011). Os trabalhos de Olson (2001, 2007) foram pioneiros nessa linha de pensamento.

Zins e Santos (2011) ao analisarem esses três sistemas de classificação, que cobrem o conhecimento universal, chegam à conclusão do que os referidos sistemas não 
apresentam de forma adequada e sistemática o conhecimento humano, na medida em que são parciais e não são sistemáticos.

Como destaca Kwasnik (1999), as classificações nunca são criadas no vazio social ou político, caracterizando-se sempre por uma estrutura hierárquica. A partir do momento em que uma classificação organiza os conceitos em classes, apresentando uma dependência entre os conceitos que a constituem, indiretamente oferece e apresenta uma descrição e uma certa visão do mundo, contribuindo, desse modo, para quem as consulta terem uma percepção deste universo conceitual. No entanto, deve considerar-se que uma classificação não é apenas um reflexo da realidade ou uma mera visão do mundo, mas, pelo fato de ser um instrumento de consulta, é um documento que prescreve como é ou como deve ser mundo (MORÁNSUÁREZ; RODRÍGUEZ BRAVO, 2001).

As classificações consideradas neste estudo (CDD e CDU) são um verdadeiro reflexo da estrutura do conhecimento existente no final do século XIX e inícios do século XX, representando as divisões científicas, culturais e sociais dos diferentes campos do conhecimento. Apesar, de em grande parte, apresentarem um reflexo de uma mentalidade positivista, elas continuam, ainda no século XXI, a serem usadas para representarem e organizarem a informação e o conhecimento, em bibliotecas e outros serviços de informação no mundo ocidental.

Partindo desse contexto, interessa investigar de que modo esses sistemas de classificação representam, na atualidade, conceitos evolutivos e complexos que se desenvolveram e se alteraram semanticamente ao longo do tempo, como é o caso do conceito "mulher". Interessa, ainda, analisar de que modo cada um dos sistemas perspectiva, através da sua representação, a expressividade desse conceito. Parte-se como hipótese de trabalho da pesquisa que o conceito de mulher é o mesmo em ambos os instrumentos, porém a pesquisa visa compreender e provar essas identidades, as suas semelhanças e, ao mesmo tempo, identificar ainda possíveis distinções. Assim, apresenta-se como objetivo geral: identificar como o conceito mulher se encontra representado no sistema de Classificação Decimal Dewey e no sistema de Classificação Decimal Universal, e se tal pode ser considerado indicador de duas perspetivas sobre o mesmo conceito - mulher. Como objetivos específicos: i) descrever os dois sistemas de classificação considerados, CDD e CDU, quanto à sua origem, função e estrutura; ii) apresentar sucintamente o conceito mulher e a sua representação na produção científica; iii) identificar a representação do conceito mulher considerando a sua exaustividade e especificidade nos dois sistemas; iv) comparar e refletir sobre essas duas abordagens. A opção metodológica assenta numa abordagem qualitativa exploratória, na qual foram privilegiadas uma revisão da literatura e a análise comparativa da representação do conceito mulher nos dois sistemas de classificação considerados.

\section{CLASSIFICAÇÃO DECIMAL DEWEY}

A Classificação Decimal Dewey(CDD) tem a sua origem em 1873 e a sua difusão é iniciada em 1876, quando Melvil Dewey, bibliotecário norte-americano, publica a sua $1^{\text {a }}$ edição. A CDD apresenta-se numa estrutura mono-hierárquica, organizada do geral para o particular, dividindo o conhecimento em 10 classes principais, cada uma delas contendo 10 divisões, por sua vez divididas em 10 seções. É atualmente considerada como o sistema de classificação bibliográfica mais utilizado mundialmente, estando traduzido em mais de 30 línguas, e é estimado que seja utilizada em bibliotecas de mais de 135 países na organização das suas coleções. Tem sido alvo de diversas 
atualizações, estando o seu desenvolvimento e manutenção a cargo de uma equipa de editores da Biblioteca do Congresso dos EUA, sendo aconselhados quanto à necessidade de revisões e atualizações por uma comissão composta por membros de diversas nacionalidades. A OCLC (Online Computer Library Center, Inc.), por seu lado, é a detentora dos direitos de publicação e licenciamento das suas edições impressa e eletrónica (OCLC, 2018).

A CDD está dividida em grandes disciplinas do saber, pois o objetivo do seu autor era ordenar os livros e a literatura científica e técnica, pelo que se impunha a utilização de áreas científicas reconhecidas (MANIEZ, 1992).

As suas classes principais organizam-se da forma seguinte (OCLC, 2018):

- 000 Ciência da computação, informação \& generalidades

- 100 Filosofia \& psicologia

- 200 Religião

- 300 Ciências sociais

- 400 Língua

- 500 Ciência

- 600 Tecnologia

- 700 Artes \& recreação

- 800 Literatura

- 900 História \& geografia

De modo a uniformizar o tratamento de algumas notações aplicáveis a todos os elementos de uma classe, ou em várias classes, Dewey criou as tabelas auxiliares, devendo posicionar-se como sufixos na construção da notação (MANIEZ, 1992). Estas tabelas são as seguintes (SIMÕES, 2011):

- tabela 1 subdivisões comuns

- tabela 2 regiões geográficas, períodos históricos e pessoas

- tabela 3 subdivisões para as artes, a literatura e gêneros literários

- tabela 4 subdivisões de língua e de famílias de língua

- tabela 5 raças, etnias e nacionalidades

- tabela 6 línguas.

Apesar da sua estrutura mono-hierárquica, a CDD apresenta, em cada nova edição, uma maior possibilidade de aplicação destas facetas (TAYLOR; JOUDREY, 2009).

Para além das tabelas principais e das auxiliares, a CDD disponibiliza o índice, consistindo numa lista alfabética dos assuntos e relações com as áreas disciplinares onde surgem.

Ao ser construída como uma classificação de base científica, para Maniez (1992) a CDD não contempla os assuntos gerais que respondem a uma visão natural do conhecimento, dando como exemplo o conceito de mulher. 


\section{CLASSIFICAÇÃO DECIMAL UNIVERSAL}

A Classificação Decimal Universal (CDU) tem a sua origem também no século XIX, conforme já referimos, mais tarde um pouco do que a CDD, pois é justamente a partir desta que é desenvolvida. Os advogados belgas Paul Otlet e Henri La Fontaine, desenvolvem, em 1895, a UDC baseada na $5^{\text {a }}$ edição da CDD e expandida com a autorização de Dewey. A $1^{\text {a }}$ edição é publicada em 1907, em francês e sob o título Manuel du repértoire bibliographique universel, surgindo, entre 1927 e 1933, a $2^{\mathrm{a}}$ edição com o título que agora se conhece. O objetivo original na criação da CDU não era a organização dos livros nas estantes de uma biblioteca, mas sim a organização de um extenso repertório bibliográfico universal (MCILWAINE, 2003).

A CDU obedece a uma estrutura mono-hierárquica, com uma relação hierárquica estabelecida em classes e subclasses, dividindo, inicialmente, o conhecimento em 10 classes principais. A classe 4, até à edição de 1962 preenchida com a linguística, agora na classe 8, não está preenchida na atualidade, estando em discussão a ocupação futura da classe vazia. Embora retomando as classes principais da CDD, a CDU distingue-se da anterior pelo seu sistema de subdivisões que permite uma análise em profundidade das matérias e pela importância acrescentada à sintaxe, através das possibilidades de combinação das tabelas auxiliares comuns e especiais (MANIEZ, 1992).

Essa classificação tem sido publicada, no todo ou em parte, em cerca de 50 idiomas diferentes, e é utilizada em serviços bibliográficos, centros de documentação e bibliotecas em 130 países em todo o mundo. A CDU é, desde 1992, propriedade do UDC Consortium, uma organização sem fins lucrativos, autofinanciada, criada para orientar o desenvolvimento e a disseminação da Classificação Decimal Universal. O consórcio foi fundado pela Federação Internacional de Documentação (FID) e pelos editores das edições holandesa, inglesa, francesa, japonesa e espanhola. O desenvolvimento e a manutenção do conteúdo da CDU são de responsabilidade do Conselho Editorial, em articulação com o Conselho Consultivo, composto por um grupo internacional de especialistas em classificação (UDCC, 2018a).

As suas classes principais organizam-se da forma seguinte (UDCC, 2018b): Ciência e Conhecimento. Organização. Informática. Informação. Documentação. Biblioteconomia. Instituições. Publicações.

- 1 Filosofia. Psicologia.

- 2 Religião. Teologia.

- 3 Ciências sociais.

- 5 Matemática. Ciências naturais.

- 6 Ciências aplicadas. Medicina. Tecnologia.

- 7 Arte. Recreação. Entretenimento. Desporto.

- 8 Língua. Linguística. Literatura.

- 9 Geografia. Biografia. História.

As tabelas auxiliares na CDU são extensas, e as mais comuns apresentam-se da seguinte forma (UDCC, 2018a):

- tabela c Auxiliares comuns de língua

- tabela d Auxiliares comuns de forma 
- tabela e Auxiliares comuns de lugar

- tabela f Auxiliares comuns de grupos humanos, etnias e nacionalidade

- tabela g Auxiliares comuns de tempo

- tabela k Auxiliares comuns de características gerais. Propriedades, Materiais, Relações/Processos e Pessoas.

Para além das tabelas principais e das auxiliares, a CDU também disponibiliza o índice, fazendo com que, ao ser criado a partir das classes principais, reproduz a dispersão dos conceitos gerais entre várias classes diferentes (MANIEZ, 1992).

\section{CONCEITO DE MULHER E A SUA REPRESENTAÇÃO NA PRODUÇÃO CIENTÍFICA}

O termo "mulher" assume, de uma forma geral, no discurso de comunicação vários significados dependendo dos contextos.

O conceito mulher enquanto objeto de estudo, considerado no singular, começa a ser notório no discurso durante o século XIX, como se pode constatar no discurso marxista e socialista quando falam da "questão da mulher" (ANDERMAHR; LOVELL; WOLKOWITZ, 1997, p. 289).

Segundo o Dicionário da língua portuguesa contemporânea da Academia das Ciências de Lisboa (2001, p. 2.546), o termo mulher é definido como um substantivo feminino que deriva do étimo latino (Mulier, -eris) e, ainda: 1. Pessoa do sexo feminino; 2. Pessoa do sexo feminino em idade adulta (já está uma mulher); 3.Num casal, o cônjuge do sexo feminino. O Dicionário Houaiss da língua portuguesa (2003, p.2.562) apresenta, na primeira acepção, uma definição muito próxima da anterior: 1. Individuo do sexo feminino considerado do ponto de vista das características biológicas, do aspeto ou forma corporal como tipo representativo de determinada região geográfica, época etc.

Com base nas definições apresentadas pelos dois dicionários linguísticos, observa-se um ponto comum: o significado assenta na noção de sexo e gênero, enfatizando, nesta perspetiva, o aspeto biológico.

A ideia generalizada e redutora que marcou o paradigma positivista e o discurso ocidental de finais do século XIX e na $1^{\mathrm{a}}$ metade do século XX, em que o conceito de mulher assenta, essencialmente, na antropologia biológica, na qual a mulher é considerada, antes de mais uma espécie natural, é alterada a partir de meados do século XX.

A corrente positivista emergiu em França nos inícios do século XIX e consolidou-se no resto da Europa nos finais deste século e inícios do XX. Um dos principais ideólogos dessa doutrina foi Auguste Comte. Entre outros pilares, o positivismo assentava no primado da ciência e no culto do método científico. Postulava uma reorganização da sociedade assente em princípios de natureza intelectual e não social (CLÉMENT et al., 1997). Numa época em que o conhecimento era produzido e consumido pelos homens, encontrando-se vedado à maioria das mulheres, é compreensível que durante esse período se tenham concebido e consolidado ideias cujo epicentro seria o homem, relevando todas as suas atividades, atitudes e interesses, em detrimento da mulher. É nesse contexto mental e cultural que é forjado o conceito de mulher, subjugado à noção do sexo masculino.

Para a alteração ocorrida dessa atitude conceptual, contribuiu o movimento feminista, que entendeu desde sempre esse conceito como redutor e discriminatório. 
Nesse sentido, existe um consenso entre os feministas ao referirem que a mulher é um conceito socialmente construído e não biologicamente adquirido (ANDERMAHR; LOVELL; WOLKOWITZ, 1997), ideia corroborada por Beauvoir (1949) quando menciona que não se nasce mulher, mas que se faz mulher, e ainda pelo Gender equality glossary and thesaurus: "A female human being; a person assigned a female sex at birth, or a personwho defines herself as a woman". Outra importante contribuição veio da antropologia existencial, a qual, apesar de reconhecer diferenças entre homens na ordem sexual, preconiza a sua natureza na ação. De acordo com esse ponto de vista, mulher e homem possuem, à partida, as mesmas possibilidades (CAZENEUVE, 1982, p. 440). Para essa nova concepção do conceito de mulher semanticamente abrangente, de um modo geral, contribuí a inter-relação entre o plano cultural e social ocorrida ao longo do século XX, dos quais se destacam, em particular os fatores naturais, demográficos, econômicos, tecnológicos e socioculturais (MAIA, 2002).

A produção científica relativamente aos estudos sobre a mulher é fértil e secular, observando-se picos em determinados períodos, os quais se encontram relacionados com diversas realidades e contextos, tal como são exemplo os séculos XIX e XX, com os movimentos sufragista e feminista, encontrando-se o conceito de mulher intrinsecamente relacionado com a noção de feminismo, ao ponto de, por vezes, se fundir. Entre outros aspetos, esses estudos são impulsionados e alavancados, nas questões de igualdade de gênero, diferindo a sua especificidade e centralidade relativamente aos contextos históricos. Nesse sentido, nos séculos XVII e XVIII, publicam-se trabalhos sobre a igualdade no trabalho e na educação, como por exemplo, entre outros: Égalité des homme et des femmes, de Marie Le Jars de Gournay (1622); De l'égalité des deux sexes. de François Poullain de la Barre (1673); The woman's labour, de Mary Collier (1739); The education of women, de Daniel Defoe (1719); e A declaration of the rights of woman and the female citizen, de Olympe de Gouges (1791). Esses e outros assuntos continuam, na atualidade, a ser objeto de estudo na profícua literatura sobre o tema, dado o fato dos mesmos ainda persistirem em algumas sociedades por motivos culturais e/ou religiosos. Destacamse, entre outras, as questões sobre o direito ao voto, à educação ou ao divórcio (BRUSCHINI; ARDAILLON; UNBEHAUM, 1998). Ao longo do século XX, a produção científica sobre esse tema é extremamente significativa. Para tal, concorreram as alterações sociais e culturais nele ocorridos, as quais vêm impulsionar essa atividade. Destacam-se, em particular, a democratização do ensino, em alguns países, a invenção da imprensa mecanizada e as convulsões sociais, muitas das quais radicadas num capitalismo selvagem. Esses fenômenos vêm estimular e concorrer para a alteração das mentalidades, de quem produz e de quem consome esse tipo de literatura. Afeta em particular as pessoas do gênero feminino pois, como é obvio, são aquelas que mais sofrem com esta nova ordem econômico-social, e, por isso, exigem alterações na sua condição. Entre outras obras, mencionam-se: A declaration of rights for women, pela National Woman Suffrage Association (1876); An address to the public, particularly to the members of the Legislature of New-York, Proposing a plan for improving female education, de Emma Willard (1819); Brief history of the condition of women: in various ages and nations, de Lydia Maria Child (1835); The higher education of women, de Emily Davies (1866); The renaissance of girls' education in England: a record of fifty years of progress, de Alice Zimmern (1898); Women and economics, de Charlotte Perkins Gilman (1898). No século XX, a produção aumentou significativamente, em especial no que se refere aos títulos de periódicos, muitos dos quais publicados por associações e centros de igualdade de gênero, alguns dos quais sediados em instituições de ensino superior, como as universidades, que vão 
fomentar a edição de artigos e outras publicações de natureza científica. Quando se fala sobre feminismo e condição da mulher no século XX, é imperativo referir a obra de Simone de Beauvoir $O$ segundo sexo, transversal ao pensamento feminista ocidental, que veio influenciar distintas gerações ao questionar a condição da mulher na contemporaneidade, assim como ao analisar e desconstruir o mito da feminilidade.

De acordo com Fox (2011), na disciplina dos estudos de género, esse conceito é definido como um constructo social. A separação entre sexo e gênero foi sempre um objetivo feminista. Entende-se que a noção de "sexo" implica uma divisão biológica associada aos órgãos sexuais femininos e masculinos; enquanto o conceito de "gênero" reflete a influência social ou cultural dessa diferença sexual. Ainda, segundo a mesma autora, o feminismo afirma que a diferença biológica é explorada por uma sociedade patriarcal para justificar a adequação dos papéis de gênero que colocam a mulher numa posição subordinada ao homem.

\section{METODOLOGIA}

Para o cumprimento dos objetivos propostos neste trabalho, optou-se por uma abordagem metodológica qualitativa exploratória, com o objetivo de se familiarizar com a questão do estudo (GIL, 2002), assim como compreender o fenômeno através da interpretação dos dados (BARBOUR, 2014). Esta abordagem assentou em dois pontos: o primeiro, na revisão da literatura; e o segundo, em uma análise comparativa, dada a relevância que esta técnica metodológica assume na interpretação dos dados, em contexto qualitativo. A revisão de literatura teve como propósito a identificação e análise da informação relacionada com o objeto de estudo (classificações) e com os objetivos enunciados de modo a sustentá-los e problematizá-los (COUTINHO, 2015; HART, 2009; PICKARD, 2013). Nesse sentido, a revisão de literatura deu cumprimento, em particular, ao $1^{\circ}$ e $2^{\circ}$ objetivos. Entre os recursos bibliográficos consultados, destacam-se as bases de dados nacionais e internacionais, privilegiando-se os artigos científicos e as classificações bibliográficas consideradas como objeto de estudo.

Os estudos comparativos no âmbito da organização do conhecimento têm tido uma ligeira expressão ao longo do tempo, estando em franca expansão, na atualidade, sobretudo devido à implementação das tecnologias no exercício da automatização dos procedimentos.Todavia, quanto ao estabelecimento de uma sustentação teóricometodológica e sua problematização, é praticamente inexistente a referência aos pressupostos que subjazem os estudos existentes, tratando-se, na generalidade, de estudos de caso com pontual observação de enquadramento metodológico.

A necessidade e a aplicabilidade dos estudos comparativos têm sido defendidas por Lor (2012, 2014), realçando o seu valor no contexto da designada library and information science. Não sendo este o local de discussão epistemológica da designação, podemos, no entanto, realçar a validade do proposto no âmbito da ciência da informação, tal como se tem afirmado internacionalmente. $O$ autor citado especifica como estudos comparados os estudos internacionais ou transnacionais, transculturais ou transsocietais.

Os estudos internacionais e comparados em biblioteconomia tiveram o seu início no final da década de 50 da centúria passada, mantendo-se, décadas depois, a ausência de discussão metodológica (LOR, 2014). Por esse motivo, Lor aprofunda a necessidade do estabelecimento de um quadro metodológico consistente e capaz de 
ultrapassar a crítica frequente aos estudos realizados no contexto da $\mathrm{Cl}$ e dos estudos biblioteconômicos, crítica essa às lacunas que Lor intitula de "empiricismo ingênuo".

O trabalho de Lor (2014) apresenta as etapas essenciais para a constituição de um estudo comparativo:

a) Os fenômenos investigados devem ter similaridade fundamental.

b) Os fenômenos podem não ser completamente idênticos.

c) Deve haver cuidadosa delimitação e definição do objeto de estudo.

d) Deve haver descrição e análise das semelhanças e diferenças entre os vários elementos que estão a ser comparados.

e) Deve haver explicação das diferenças.

No presente trabalho, a análise comparativa deu cumprimento ao $3^{\circ}$ e $4^{\circ}$ objetivos estabelecidos e assentou na análise do corpus do estudo, que teve como base os dados recolhidos nos dois sistemas de classificação: Classificação Decimal Dewey e Classificação Decimal Universal. Pressupôs três momentos: i) apresentação e caraterização do conceito de mulher e a sua representação na produção científica; ii) definição das categorias a considerar no levantamento dos dados e análise respectiva: especificidade e exaustividade; iii) recolha dos dados para a qual foi construída um quadro, cujos dados nele registados deram origem a gráficos que manifestam as percentagens das categorias consideradas como objeto da análise comparativa entre os dois sistemas de classificação.

Para a recolha dos dados, partiu-se, como referido, dos dois sistemas de classificação considerados: Classificação Decimal Dewey e Classificação Decimal Universal. No primeiro, foi utilizado a Guide de la classification décimale de Dewey: tables abrégées e a $22^{\text {a }}$ edição integral em língua inglesa (BÉTHERY, 2005). No segundo, La Clasificación Decimal Universal (CDU), edição abreviada (2016).

A escolha desses dois sistemas de classificação prende-se com o fato de, por um lado, apresentarem a mesma estrutura dada a circunstância da Classificação Decimal Universal se basear na Classificação Decimal Dewey; por outro lado, porque um se desenvolveu na Europa, onde tem um uso relevante (Classificação Decimal Universal), e o outro nos Estados Unidos da América, o que permitirá ter duas perspectivas diferentes quanto à representação dos assuntos, em particular sobre os mesmos assuntos, como é o caso do objetivo do presente estudo.

O levantamento das notações fez-se partindo dos respectivo índice dos sistemas, tendo sido estas conferidas nas tabelas. Esse procedimento foi complementado com a revisão das próprias tabelas principais e auxiliares, naquelas classes em que a probabilidade da existência do conceito nos pareceu mais evidente, como no caso da classe 3. Conforme as notações eram identificadas, elas foram registadas numa tabela criada para o efeito.

Para a análise dos resultados, foram criadas duas categorias: exaustividade e especificidade. A escolha destas duas categorias prende-se com o facto de, por um lado a exaustividade traduzir o número de vezes em que este conceito surge em cada sistema e em cada classe em particular, circunstância que dita a sua ocorrência no que se refere ao geral e ao particular. A especificidade manifesta o nível de peculiaridade com que este assunto é representado, fato que irá concorrer para inferências sobre o interesse desse assunto nos respetivos sistemas. Considerando a estrutura dos mesmos em particular a hierarquia das classes (geral para o particular), 
a leitura far-se-á no mesmo sentido. Isto é: quanto mais geral (abreviada) for a notação, maior será a sua relevância nos sistemas, pois a extensão semântica conferida às classes, subclasses e divisões é maior quando comparada com as subdivisões. Além do que, permitem um desenvolvimento conceitual, dos assuntos nelas representadas, maior do que as subdivisões.

Quadro 1: Notações representativas do conceito mulher em termos de exaustividade e especificidade nos dois sistemas de classificaçãoe respectiva transcrição para linguagem natural.

\begin{tabular}{|c|c|c|c|c|}
\hline & EXAUSTIVIDADE & ESPECIFICIDADE & TRANSCRIÇÃO PARA LINGUAGEM NATURAL \\
\hline \multirow{14}{*}{ CDD } & \multirow{12}{*}{$\begin{array}{l}\text { Classes } \\
\text { principais }\end{array}$} & 0 & 070.483 & Imprensa feminina \\
\hline & & 1 & 155.633 & Psicologia de adultos (mulher) \\
\hline & & 2 & $255 \cdot 9$ & Congregações e ordens católicas femininas \\
\hline & & \multirow{6}{*}{3} & 305.4 & Homens e mulheres - género (Mulher) \\
\hline & & & 331.4 & Mão de obra feminina \\
\hline & & & $355 \cdot 348$ & Vida militar (serviço feminino) \\
\hline & & & 362.83 & Assistência social (Mulher) \\
\hline & & & 371.822 & Estudantes (Mulher) \\
\hline & & & 391.2 & Costume e aparência pessoal (costumes femininos) \\
\hline & & 6 & $618.1 / .8$ & Ginecologia e obstetrícia \\
\hline & & 7 & 704.042 & $\begin{array}{l}\text { Belas-artes e artes decorativas - segundo o sexo } \\
\text { (Mulher) }\end{array}$ \\
\hline & & 9 & 920.72 & Biografia (Mulher célebre) \\
\hline & Soma & 7 & 12 & \\
\hline & Auxiliares & \multicolumn{2}{|l|}{-082} & Mulher \\
\hline \multirow{8}{*}{ CDU } & \multirow{6}{*}{$\begin{array}{l}\text { Classes } \\
\text { principais }\end{array}$} & 1 & 141.72 & Feminismo \\
\hline & & \multirow{2}{*}{6} & 614.253 .5 & Enfermeiros. Pessoal auxiliar. Parteiras \\
\hline & & & 618.1 & Ginecologia. Doenças da mulher \\
\hline & & \multirow{3}{*}{7} & $791-52$ & Heroínas \\
\hline & & & $791-55$ & Mulheres vilãs \\
\hline & & & $791-56$ & Mulheres fatais \\
\hline & Soma & 3 & 6 & \\
\hline & Auxiliares & $\begin{array}{l}-055.2 \\
-055.25 \\
-055.26\end{array}$ & & $\begin{array}{l}\text { Pessoas do sexo feminino. Mulheres } \\
\text { Meninas } \\
\text { Mulheres grávidas }\end{array}$ \\
\hline
\end{tabular}

Fonte: elaborado pelos autores a partir de dados da pesquisa (2018). 


\section{APRESENTAÇÃO E DISCUSSÃO DOS RESULTADO}

O primeiro resultado que se observa ao analisar o corpus de estudo prende-se com a escassa presença do conceito mulher nos dois sistemas de classificação. Tal observância justifica-se pelo fato de estes sistemas de classificações ainda reproduzirem, em parte, a mentalidade positivista em que foram concebidos, na qual o gênero masculino é considerado como universal e genérico, refletindo, desse modo, a sociedade androcêntrica em que continuamos a viver. Por outro lado, a especificidade do gênero feminino é transmitida em notações redutoras da presença feminina no universo familiar, social e laboral.

\section{Exaustividade}

Interessa salientar que apesar da escassez da ocorrência deste conceito na CDD, este é, contudo, registado nas classes principais (70\%), surgindo apenas uma vez nas tabelas auxiliares, com a notação -082.

Na CDD, verificam-se sete ocorrências em dez classes, a saber: zero, um, dois, três, seis, sete e nove.

\section{Figura 1. Percentagem de classes principais na CDD com ocorrências do conceito mulher.}

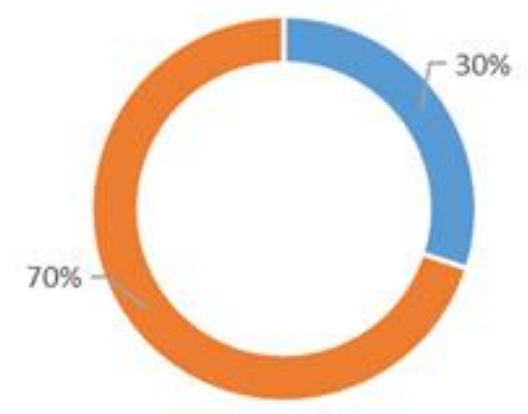

Classes principais

n ausência do conceito

- presença do conceito

Fonte: elaborado pelos autores a partir de dados da pesquisa (2018). 


\section{Figura 2. Distribuição de ocorrências do conceito mulher nas classes principais da}

CDD.

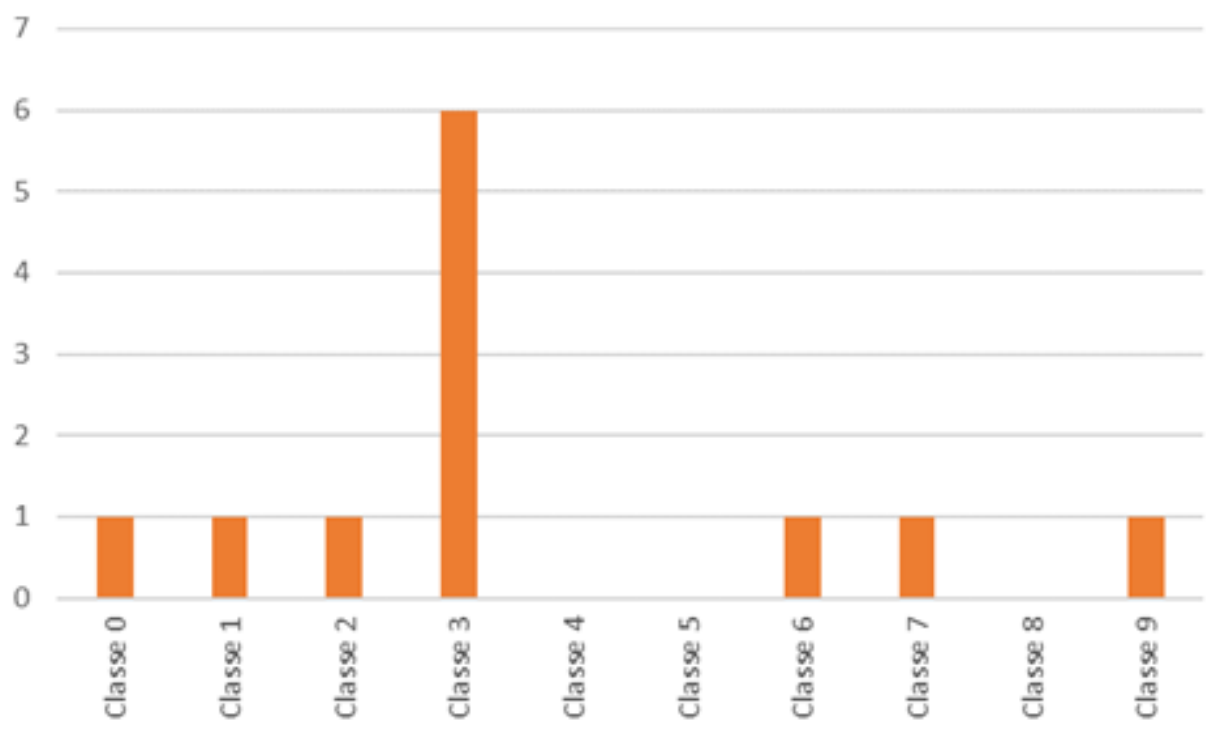

Fonte: elaborado pelos autores a partir de dados da pesquisa (2018).

Excetuando-se a classe 300 Ciências sociais, na qual o conceito mulher ocorre seis vezes nas outras classes observa-se apenas uma ocorrência em cada classe

Interessa referir que, excetuando a subclasse 330 Economia, a ocorrência deste conceito, onde aparece associado à mão de obra na notação 331.4, não se observa em outras subclasses com igual representatividade conceitual, tal como: economia financeira ou economia internacional, 332 e 337, respectivamente. Esse registro enquadra-se no espírito da concepção desse sistema de classificação e reproduz a mentalidade e a cultura da época. Outro indicador da presença da mentalidade positivista, no que concerne a este conceito, tem a ver com o seu registro nas notações 391.2 e 704.042, onde representa a mulher com características associadas a conceitos que traduzem particularidades que, de um modo geral, são depreciativas.

Observam-se, contudo ocorrências desse conceito nesse sistema que manifestam a capacidade da sua estrutura decimal em assimilar novas perspectivas de conceitos evolutivos, como é o caso das notações 155.633 Psicologia de adultos (mulher) subclasse 150 Psicologia; 355.348 Vida militar (serviço feminino) - subclasse 355 Ciência militar e, 371.822 Estudantes (Mulher), subclasse 371 Estabelecimentos de ensino e suas atividades. Educação especial.

No caso da CDU, o conceito mulher tem vindo a desaparecer desde a edição de 1995, como se pode observar num trabalho que compara a imagem da mulher daquela edição com a de 2000 (MORÁNSUÁREZ; RODRÍGUEZ BRAVO, 2001). Essa situação é evidente na última edição abreviada de 2016, usada neste estudo.

Assim, o primeiro resultado que se observa é a escassez da presença desse conceito nas classes principais, sendo apenas registado em tr classes (30\%), a saber: 1 Filosofia. Psicologia; 6 Ciências aplicadas. Medicina. Tecnologia, e 7 Arte. Recreação. Entretenimento. Desporto.

Apresenta uma ocorrência significativa nos auxiliares -05 Auxiliares comuns de pessoa e características pessoais, situando-se todos os registros no desenvolvimento da 
notação -055 Pessoas de acordo com o sexo e o parentesco; a saber: Pessoas do sexo feminino. Mulheres - 055.2; Meninas -055.25; Mulheres grávidas-055.26.

Neste sistema abundam exemplos nos quais se podem utilizar:

- 616-051 Pessoal médico: médicos, enfermeiras, etc.

- 324-052-055.2 Mulheres eleitas

- 347.96-055.2 Advogadas

- 64-053.6-055.2 Pessoal doméstico feminino adolescente

A utilização do auxiliar de pessoa mulher associado a uma notação principal permite representar a particularidade deste conceito num determinado contexto.

Figura 3. Percentagem de classes principais na CDU com ocorrências do conceito. mulher

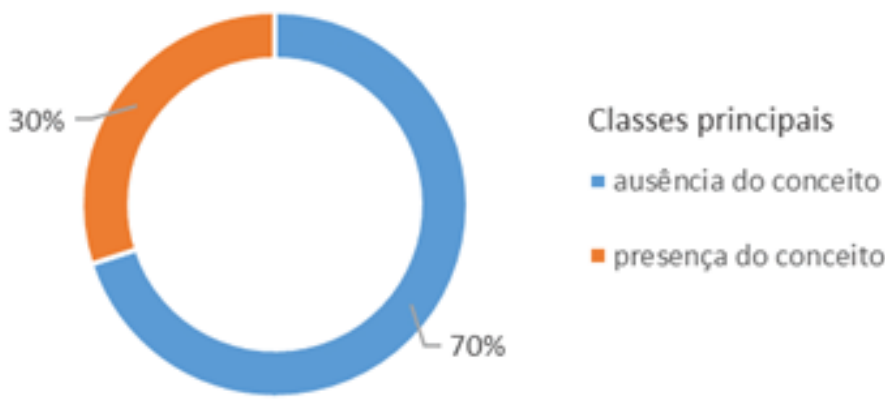

Fonte: elaborado pelos autores a partir de dados da pesquisa (2018).

Interessa referir que nas classes principais, esse conceito apresenta duas ocorrências na subclasse 61 Ciências médicas; três na subclasse 79 Divertimentos. 
Figura 4. Distribuição de ocorrências do conceito mulher nas classes principais da

4

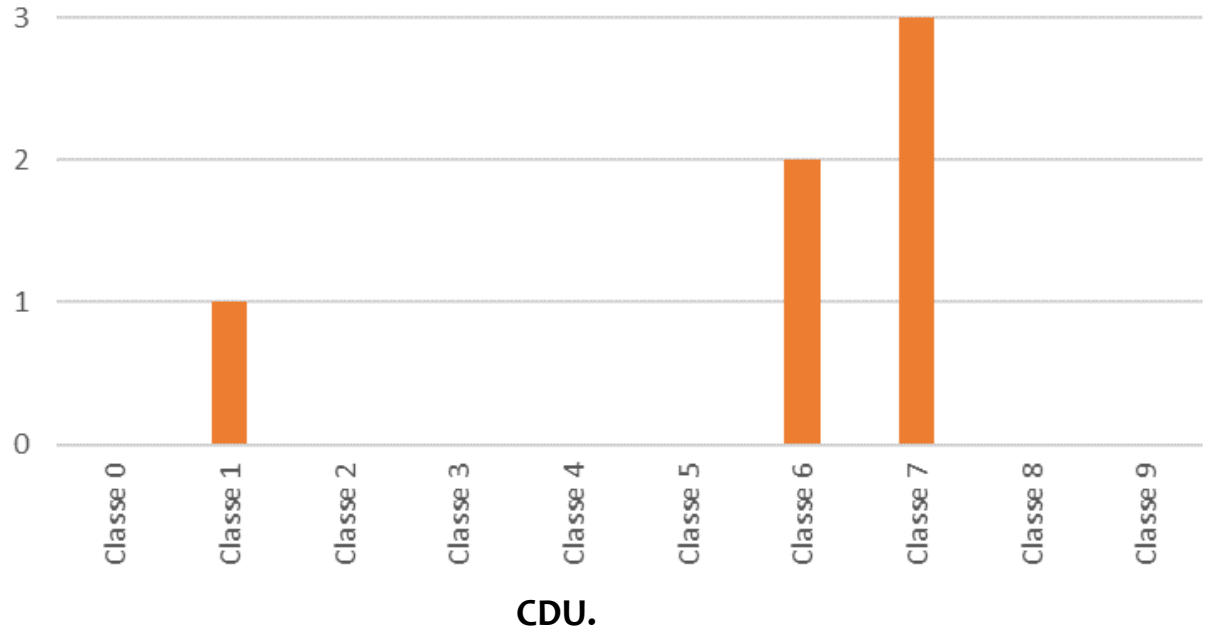

Fonte: elaborado pelos autores a partir de dados da pesquisa (2018).

Espetáculos. Jogos. Desportos; e uma no 14 Sistemas e pontos de vista filosóficos.

Relativamente ao registro do conceito mulher nas classes principais, interessa salientar, por um lado, a dupla ocorrência na subclasse 61: 614.253.5 Enfermeiros. Pessoal auxiliar. Parteiras; e na 618.1 Ginecologia. Doenças da mulher. A representação desse conceito nessas duas notações as reforçam uma ocupação laboral, tradicionalmente assumida pelas mulheres, a primeira notação; e a segunda encontra-se associada à própria condição biológica da mulher, o mesmo acontecendo com o auxiliar -055.26. É, no entanto, importante referir que algumas dessas interpretações são destacadas devido à tradução para línguas como o espanhol ou o português, pois em inglês pelo menos as designações profissionais não apresentam gênero.

Por outro lado, é de destacar o registro na divisão 791 com os respectivos auxiliares que representam caraterísticas estereotipadas da mulher e divulgadas através do cinema, entre outros meios, que se podem identificar com uma posição positivista desse conceito, como é exemplo a notação 791-56, Mulheres fatais, não se observando uma notação para o mesmo conceito relativo ao género masculino.

Observa-se o registro do conceito feminismo na subclasse 14 "Sistemas e pontos de vista filosóficos", quando nas edições anteriores a 2000 se encontrava na notação 396 "Feminismo. Situação das mulheres".

Com essa substituição, na classe 3 da CDU deixou de se observar qualquer referência a esse conceito, o que em nada o prestigia, na medida em que essa classe é pela sua natureza aquela que representa os assuntos relacionados com os aspetos sociais, nos quais a mulher tem um papel relevante.

\section{Especificidade}

Quanto à representação desse conceito em termos de especificidade nas classes em que é mencionado, tendo em conta a estrutura das classes desses dois sistemas, 
observamos que ele é sempre traduzido recorrendo-se a um significativo nível de detalhe das notações, por isso, é sempre representado nas subdivisões. Esta constatação, de acordo com a estrutura hierárquica das classes, revela a pouca importância desse conceito nesses dois sistemas de classificação. Nesse sentido, registra-se um posicionamento de grande particularidade nos conceitos relacionados com a mulher. Em nenhum caso se localiza em primeiro lugar, na subclasse ou na divisão, registrando-se entre quatro e seis dígitos decimais na CDD e três (com auxiliares) e sete na CDU.

\section{Comparação dos resultados nos dois sistemas de classificação considerados}

Quanto à exaustividade, observa-se um nível reduzido na representação desse conceito nos dois sistemas de classificação estudados, acentuando-se uma presença mais relevante nas tabelas principais da CDD, quando comparadas com as da CDU, observando-se o oposto no que respeita aos auxiliares comuns, no caso ao auxiliar comum de pessoa, que é mais significativo na CDU.

Nas classes principais, existe apenas uma coincidência numa notação da classe principal 6, subclasse 61 Medicina (618.1 de Ginecologia. Patologia das mulheres), que como referimos apresenta uma caraterística biológica da mulher, ou aspetos a ela associados, o que demonstra as suas raízes positivistas.

A diferença mais significativa neste estudo prende-se com a presença mais acentuada desse conceito na CDD, nas classes principais (70\%), ao contrário do que acontece com os auxiliares. Outra diferença tem a ver com a ausência desse conceito na classe 3 da CDU, devido à eliminação da notação 396, como foi registrado, ao contrário da $\mathrm{CDD}$, onde ocorre seis vezes.

\section{CONSIDERAÇÕES FINAIS}

A primeira inferência a registrar é o fato de não se observarem duas perspectivas diferentes em relação ao conceito mulher, apesar de historicamente os dois sistemas de classificação considerados se terem desenvolvidos em duas culturas diferentes, pese embora serem ocidentais: a cultura anglo-saxônica (CDD) e a cultura latina $(C D U)$.

De um modo geral, partindo do observado, os dois sistemas continuam a traduzir a mentalidade positivista na qual foram concebidas, tornando-se motivo de reflexão, sobretudo, se se considerar que a criação da CDD ocorreu a cerca de um século e meio.

Infere-se que apesar de se assistir à tentativa dos dois sistemas considerados, CDD e CDU, estarem a evoluir no sentido de evitar estereótipos, na verdade continuam a demonstrar desigualdade e anacronismo na representação de alguns conceitos complexos e evolutivos, no caso o conceito mulher. Reflexo desta posição foi a eliminação, na atual edição da CDU, da notação 647.2 Pessoal que trabalha em casa. Serviço doméstico, índice que revela um dos papéis laborais tradicionais associados à mulher; contudo, a posição desfavorável da mulher é notória, no cinema - filmes 791, onde a mulher assume certas características femininas com caráter depreciativo, como no caso de 791-56 (Mulheres fatais). 
No estudo, é evidente a reduzida representatividade do conceito mulher nos dois sistemas de classificação estudados, quer no que se refere à exaustividade, quer no que concerne à especificidade.

Os dois sistemas refletem, assim, a noção de mulher num plano depreciativo e inferior à masculina, traduzindo, desse modo o estereótipo tradicional.

No que concerne ao registro do conceito feminismo na subclasse 14 "Sistemas e pontos de vista filosóficos", infere-se que essa introdução tenha o propósito de conferir a esse conceito uma perspetiva epistemológica. Contudo, a noção relacionada com a perspectiva pragmática do mesmo perdeu-se nas edições posteriores a 2000, na medida em que se extinguiu a notação 396 "Feminismo. Situação das mulheres", que traduzia a ideia - situação da mulher.

A opção de ser considerado, nessa última edição da CDU, o auxiliar de pessoa em vez de estar reservado um espaço para a representação do conceito mulher na notação 396, concorre para o detrimento da visibilidade desse conceito nesse sistema de classificação. Contudo, resulta num procedimento mais paritário com o masculino, na mediada em que este tem igual tratamento.

Artigo recebido em 05/07/2018 e aprovado em 04/10/2018.

\section{REFERÊNCIAS}

ACADEMIA DAS CIENCIAS DE LISBOA. Dicionário da língua portuguesa contemporânea. Lisboa: Verbo, 2001.

ANDERMAHR, S.; LOVELL, T.; WOLKOWITZ, C. A glossary of feminist theory. London: Arnold, 1997.

BARBOUR, R. Introducing qualitative research: a student's guide. London: Sage, 2014.

BÉTHERY, A. Guide de la classification décimale de Dewey: tables abrégées e la XXII edition intégraleen langue anglaise. Paris: Cercle de la Libraire, 2005.

BEAUVOIR, Simone. Le deuxiéme sexe. Paris: Gallimard, 1949.

BRUSCHINI, C; ARDAILLON, D.; UNBEHAUM, S. G. Tesauro para estudos de gênero $e$ sobre mulheres, $1998 . \quad$ Disponível em: <http://www.fcc.org.br/conteudosespeciais/tesauro/arquivos/TPEDGESM.pdf >.

Acesso em: 15 abr. 2018.

CAZENEUVE, J. (Coord.). Dicionário de sociologia. Lisboa: Verbo, 1982.

CLASIFICACIÓN DECIMAL UNIVERSAL (CDU). Madrid: Aenor, 2016.

CLÉMENT, E. et al. Dicionário prático de filosofia. Lisboa: Terramar, 1997.

COUTINHO, C. Metodologia de investigação em ciências sociais. Coimbra: Almedina, 2015.

FOX, M. J. Prototype theory: an alternative concept theory for categorizing sex and gender? Knowledge Organization, v. 38, n. 4, p. 328-334, 2011.

. Subjects in doubt: the ontogeny of intersex in the Dewey Decimal Classification. Knowledge Organization, v.43, n. 8, p. 581-593, 2016. 
GIL, A. C. Como elaborar projetos de pesquisa. São Paulo: Atlas, 2002.

HART, C. Doing a literature review: releasing the social science research imagination. Londres: Sage, 2009. Disponível em: <http://doi.org/10.1080/01422419908228843>. Acesso em: 5 abr. 2018.

HOUAISS, A.; VILLAR, M. de S.; FRANCO, F. M. de M. Dicionário Houaiss da língua portuguesa. Lisboa: Temas e Debates, 2003. v. 3.

KWASNIK, B. H. (1999). The role of classification in knowledge: representation and discovery. LibraryTrends, v. 48, n.1, p. 22-47, 1999.

LOR, P. J. Revitalizing comparative library and information science: theory and metatheory. Journal of Documentation, v. 70, n. 1, p. 25-51, 2014. Disponível em: <doi.org/10.1108/JD-10-2012-0129>. Acesso em: 7 abr. 2018.

.Towards excellence in international and comparative research in library and information science. In: WORLD LIBRARY AND INFORMATION CONGRESS: IFLA GENERAL CONFERENCE AND ASSEMBLY, 78., 2012, Helsinki. Disponível em: <https://www.ifla.org/past-wlic/2012/105-lor-en.pdf>. Acesso em: 5 abr. 2018.

MAIA, R. L. (Coord.). Dicionário de sociologia. Porto: Porto Editora, 2002.

MANIEZ, J. Los lenguajes documentales y de clasificación: concepción, construcción y utilización en los sistemas documentales. Madrid: Fundación Germán Sanchez Ruipérez, 1992.

MCILWAINE, I.C. Guía para el uso de la CDU. Madrid: AFNOR, 2003.

MORÁN SUÁREZ, M. A.; RODRÍGUEZ BRAVO, B. La imagen de la mujer en la Clasificación Decimal Universal (CDU). In: V CONGRESO Isko-España: la representación y organización del conocimiento: metodologías, modelos y aplicaciones: actas del congreso, 25, 26 y 27 de abril de 2001, Alcalá de Henares (Madrid-España). Alcalá de Henares: Facultad de Ciencias de la Documentación, Universidad de Alcalá de Henares, 2001. (Organización del Conocimiento en Sistemas de Información y Documentación, 5)

OCLC ONLINE COMPUTER LIBRARY CENTER, INC. Dewey Decimal Classification ${ }^{\circledR}$ (DDC $($ ) summaries: a brief introduction to the Dewey Decimal Classification system. 2018. Disponível em: <https://www.oclc.org/en/dewey/features/summaries.html\#dev>. Acesso em: 4 abr. 2018.

OLSON, H. A. How we construct subjects: a feminist analysis. Library trend, v. 56, n. 2, p. 509-541, 2007.

. Sameness and difference: a cultural foundation of classification. Library Resources \& Technical Services, v. 45, p. 115-122, 2011.

PICKARD, A. J. Research methods in information. London: Facet Publushing, 2013.

SIMÕES, M. G. Classificações bibliográficas: percurso de uma teoria. Coimbra: Almedina, 2011.

TAYLOR, A. G.; JOUDREY, D. N. The organization of information. 3. ed. Westport, CT: Libraries Unlimited, 2009.

UDCC UNIVERSAL DECIMAL CLASSIFICATION CONSORTIUM. Universal Decimal Classification., 2018a. Disponível em: <http://www.udcc.org/>. Acesso em: 20 mar. 2018. 
.Universal Decimal Classification summary, 2018b. Disponível em: <http://www.udcsummary.info/>. Acesso em: 20 mar. 2018.

ZINS, CH.; SANTOS, P. L. V. A. C. Mapping the knowledge covered by library classification systems. Journal of the American Society for Information Science and Technology, v. 62, n. 5, p. 877-901, 2011. 